\title{
RAZÃO TEÓRICA E RAZÃO PRÁTICA EM KANT*
}

Thadeu Weber"

SINTESE - O estabelecimento de um paralelismo entre razão teórica e razão prática permite explicitar o âmbito de cada uma delas. A restrição do uso da razão assegura, por um lado, o caminho seguro da ciência e mostra, por outro lado, que há um uso prático da razão - a moral, isto é, que ela pode determinar imediatamente a vontade. PALAVRAS-CHAVE - ciência, moral, razão.
ABSTRACT - This article establishes a parallelism between theoretical reason and practical reason to elucidate each other. The restriction of the reason's use shows two different proceedings: the safety science's method and a practical use of reason - the morality - this means that the reason can just determinate the desire.

KEY-WORDS - science, morality, reason.

A busca e determinação de um principio último de moralidade é o objetivo central da filosofia prática de Kant. Legitimo filho do Iluminismo, aposta na autonomia da razão e na "maioridade" do homem. Encontra no "uso público" da razão a defesa incondicional da liberdade.

Sua filosofia moral deve, no entanto, ser devidamente situada a partir da filosofia do conhecimento desenvolvida na Crítica da Razão Pura. Isto inclui uma clara delimitação do âmbito da razão teórica e da razão prática; ou seja, deve-se submeter a razão à avaliação de si mesma, isto é, à crítica. O problema, portanto, é investigar como pode uma razão pura ser prática, ou seja, como pode a razão determinar não só as condições do conhecimento, mas também, imediatamente, a vontade. Em vista disso, o intuito primeiro é mostrar como se dá a passagem da razão teórica para a razão prática.

A delimitação do uso teórico e do uso prático da razão, em Kant, pode partir de uma descrição inicial de sua concepção de ciência. Questões como estas devem ser examinadas: Quando é que estamos fazendo ciência? Qual é o critério?

* O presente artigo é um capítulo de uma pesquisa sobre a crítica de Hegel ao formalismo da moral kantiana.

** Diretor do Instituto de Filosofia e Ciências Humanas da PUCRS.

\begin{tabular}{|l|l|l|l|l|l|}
\hline VERITAS & Porto Alegre & v. 42 & $\mathrm{n}^{\mathbf{0}} 4$ & Dezembro 1997 & p. 913-921 \\
\hline
\end{tabular}


Segundo o filósofo da Crítica da Razão Pura, é o resultado atingido num determinado conjunto de conhecimentos que indica se foi alcançado o "caminho seguro de uma ciência" (C. R. Pura, prefácio). Se forem necessários constantes retornos ou se cairmos em seguidas contradições, é sinal que estamos ainda num "simples tatear". Ora, a lógica, a matemática e a ciência da natureza, sobretudo com Galileu, são exemplos de conhecimentos que atingiram o caminho seguro de uma ciência. ${ }^{1}$ Seu resultado, dada sua delimitação, necessidade e universalidade, é a comprovação disso.

Apoiado nas ciências constituídas no seu tempo, Kant promove uma verdadeira revolução na teoria tradicional do conhecimento. A lição aprendida é que "a razão só compreende o que ela mesma produz segundo seu projeto" ( $C$. R. Pura, pref.). Isto significa que o pesquisador ou o cientista deve exigir que a natureza responda às suas perguntas, de acordo com um projeto previamente elaborado. Observações feitas ao acaso, sem um plano previamente projetado não são compreendidos pelos sujeitos investigadores ou não tem importância para eles, considerando que não conseguem ligá-las a uma lei necessária. Um juiz obriga a testemunha a responder às perguntas que ele próprio formula porque está fazendo ciência jurídica; isto é, ele está conduzindo o processo de investigação e deverá esclarecer questões atinentes a este processo. Igualmente a razão prática só compreende a lei que ela mesma se dá. Por isso, o homem só é livre quando cumpre a lei moral que ele mesmo se dá. O conceito de autonomia da vontade está, como veremos, intimamente ligado com este conceito de liberdade. Considerando que não se pode buscar a lei moral em algum conteúdo material empírico, deve-se determiná-la pela própria razão.

O fato é que se impõe um a priori nas ciências, considerando que deve haver, nelas, razão. Ora, que deva haver um a priori nas ciências significa que algo deve ser dado antes que os objetos do conhecimento, ou, no caso da razão prática, algo tem que ser dado antes das ações. Como o a priori só é possivel no sujeito que investiga, é este que vai referir-se ao objeto. São dois os modos pelos quais o conhecimento da razão pode referir-se ao seu objeto: a) para determinar este e seu conceito; é o conhecimento teórico; b) para torná-lo real; é o conhecimento prático (cf. C. R. Pura, p. 10). Ora, o a priori somente é possivel na razão ou no sujeito porque só daí poderá resultar a necessidade e a universalidade. Isto não é possivel partindo-se do objeto. Deste só se pode ter o particular e o contingente.

Uma revolução, análoga à que fez Copérnico e inspirada nos físicos modemos, foi necessária no plano do conhecimento, a fim de tornar possivel este a priori. Galileu e Torricelli deram-se conta de que eles deveriam determinar as condições de seus experimentos, ou como diz Kant, "quando Galileu deixou suas esferas rolar sobre a superfície oblíqua com um peso por ele mesmo escolhido, ou quando Torricelli deixou o ar carregar um peso de antemão pensado como igual ao de uma coluna de água conhecida por ele" (C. R. Pura, prefácio), deram-se conta que só estavam compreendendo aquilo que se adequava ao seu projeto. Analogamente a isto Kant propõe uma inversão na teoria tradicional do conhecimento, a fim de possibilitar o a priori. "Até agora se supôs que todo o nosso conhecimento tinha

Por ciência deve-se entender, aqui, a ciência empírica. 
que se regular pelos objetos; porém todas as tentativas de mediante conceitos estabelecer algo a priori sobre os mesmos, através do que ampliaria o nosso conhecimento, fracassaram sob esta pressuposição. Por isso tente-se ver uma vez se não progredimos melhor nas tarefas da metafísica admitindo que os objetos têm que se regular pelo nosso conhecimento, o que concorda melhor com a requerida possibilidade de um conhecimento a priori dos objetos que deve estabelecer algo sobre os mesmos antes de nos serem dados" (C. R. Pura, p. 12). A possibilidade de um conhecimento a priori dos objetos é o aspecto fundamental evidenciado pelo autor. É isto que constitui a ciência, uma vez que garante resultados seguros (necessários e universais). Se é o sujeito quem estabelece as condições do conhecimento, sujeitos diferentes repetindo as mesmas condições deverão chegar aos mesmos resultados. Isto é ciência. Dizer algo a priori sobre a água, significa enquadrá-la numa lei necessária: que, por exemplo, ela ferve aos $100^{\circ}$ centígrados. Todo líquido que tiver como constitutivos duas moléculas de hidrogênio e uma de oxigênio sabe-se a priori que é água e que ferve aos 100 graus. As condições de temperatura, por exemplo, são estabelecidas pelo sujeito investigador e não determinadas pelo objeto investigado. Logo, sujeitos diferentes, nas mesmas condições obterão os mesmos resultados. Eis a lei.

O paralelismo entre a Critica da Razão Pura e a Crítica da Razão Prática indica que se a razão determina a prion as condições de possibilidade do conhecimento deve também determinar a priori a vontade dos sujeitos agentes através do imperativo categórico, para que seus atos tenham valor moral. A primeira é a função da razão pura teórica, a segunda é a função da razão pura prática. É a mesma razão pura com uma dupla função ou aplicação. A preocupação central de Kant é com a parte pura de ambas. Na Crítica da Razão Pura demonstra como é possível uma razão pura teórica, ou seja, mostra quais são as condições de possibilidade do conhecimento. $\mathrm{Na}$ filosofia moral procura demonstrar como a razão pura pode ser prática. Observe-se bem o segundo momento: a razão pura, e não uma razão empírica, pode ser prática, porquanto já submetida a uma prévia crítica. Este é o tema central da filosofia moral kantiana (cf. também Beck, 1980, p. 41). Se ao nível do conhecimento o sujeito não pode ser determinado pelo objeto, uma vez que deste não pode resultar a necessidade e a universalidade, ao nivel do agir moral 0 empirico não pode fornecer o princípio de determinação das vontades dos sujeitos agentes, dado que dele (do empírico) só se origina o particular e o contingente. A razão deve, portanto, poder determinar por si mesma as ações com verdadeiro mérito moral. Convém salientar que os princípios nos quais se baseia a razão pura, tanto teórica como prática, são sempre a priori, isto é, independentes da experiência. Em outras palavras, se as condições de possibilidade do conhecimento são a priori, os princípios da razão prática também deverão ser proposições independentes de toda e qualquer experiência, isto é, de qualquer intuição material. Esta não poderá dar a universalidade e a necessidade que são as exigências da lei moral. Ou seja, esgotados os limites do campo da experiência (razão teórica) não se pode recorrer a ela para fundamentar as leis da razão prática.

Isto evidencia a unidade da razão (teórica e prática), na perspectiva kantiana. O que faz com que se trate de uma só razão e razão pura é que seus princípios são 
a priori. Se o que há de comum é o a priori, o que as distingue, como dissemos, é sua diferente aplicação.

A mesma "inversão copernicana" efetuada por Kant em relação ao conhecimento (Crítica da Razão Pura) deve ser feita no campo da ética. Esta é a condição de possibilidade de os principios da razão serem a priori e, assim, necessários e universais. Uma alusão à "revolução copernicana" na ética já encontramos na Fundamentação da Metafísica dos Costumes: "Uma ação praticada por dever tem seu valor moral, não no propósito que com ela se quer atingir, mas na máxima que a determina. Não depende, portanto, da realidade do oḅjeto da ação, mas somente do princípio do querer segundo o qual a ação, abstraindo de todos os objetos da faculdade de desejar, foi praticada" (p. 30). O caráter a priori, portanto, exige a pureza da razão enquanto determinante da vontade do sujeito agente.

Se nos voltarmos um pouco mais sobre a "inversão copernicana" promovida por Kant na Crítica da Razão Pura, podemos avaliar com mais precisão os resultados que esta "crítica" traz para as pretensões da metafísica. ${ }^{2}$ Verificamos de imediato que, por um lado, é possivel explicar a possibilidade do conhecimento a priori; mas, por outro, "não podemos ultrapassar os limites da experiência poscível", que é exatamente o interesse da metafísica (C. R. Pura, p. 13). Ou seja, desta crítica da razão (que mostra suas fontes e seus limites) resulta que só podemos conhecer os fenômenos (as coisas na medida em que aparecem no âmbito do espaço e do tempo e podem ser pensadas ao nivel dos conceitos puros do entendimento) e não as coisas em si mesmas. Mas a razão exige um incondicionado para todo condicionado. Para os fenômenos ela exige a "completude da série das condições". Só que o incondicionado somente pode ser encontrado nas coisas em si mesmas, portanto não pode ser conhecido. Mas como sei que existe? É um salto metafísico que leva a ele como resultado da síntese do pensamento.

É oportuno lembrar que o incondicionado tem, em Kant, uma dúplice significação: uma que o considera como completude da série das condições, outra uma causalidade por liberdade, uma causalidade que se determina por si mesma. Para as pretensões da filosofia prática interessa, principalmente, a segunda significação. $\mathrm{Na}$ Crítica da Razão Prática, lemos: "A determinação da causalidade dos deveres no mundo sensível como tal nunca podia ser incondicionada e, não obstante, deve necessariamente haver, para toda série das condições, algo de incondicionado, por conseguinte, também uma causalidade que se determina inteiramente por si mesma” (p. 61). O acesso ao incondicionado, seja ele uma Idéia da razão, isto é, Deus, ou seja ele a própria razão que determina imediatamente a vontade, uma causalidade por liberdade, sem ser determinada por algo externo a ela, só é possível no plano metafísico.

Mas a crítica nega à razão especulativa todo avanço no campo suprasensivel; ela representa uma restrição do uso da razão, exatamente porque mostra

Na Crítica da Razão Pura, Kant diz que a metafísica é "um conhecimento especulativo da razão inteiramente isolado que através de simples conceitos (não como a matemática, aplicando os mesmos à intuição), se eleva completamente acima do ensinamento de experiência na qual portanto a razão deve ser aluna de si mesma" (Prefácio $p$. 11). Também na introdução refere-se à metafísica como conjunto de conhecimentos que se "elevam acima do mundo sensivel" (p. 25). É desta concepção de metafísica que estamos tratando aqui. 
suas capacidades. Tem a função de purificar a metafísica. A "crítica" é uma "ciência da simples avaliação da razão pura, das suas fontes e de seus limites ...; é a propedêutica ao sistema da razão pura" (C. R. Pura, introd.). O resultado desta crítica é que só conhecemos as coisas tal como aparecem e não como são em si mesmas.

A distinção entre fenômeno e coisa em si (proporcionada pela critica) permite a Kant solucionar um grande problema no que se refere ao incondicionado, enquanto idéia da razão. Se o nosso conhecimento se regulasse pelos objetos, tomados como coisas em si mesmas, não se poderia pensar o incondicionado sem cair em contradição. É que os objetos, na experiência, se manifestam sob diferentes aspectos e 0 incondicionado, enquanto "completude da série das condições", só pode ser um. Por isso ele não pode ser encontrado nas coisas na medida em que as conhecemos, isto é, nos fenômenos, mas deve poder ser pensado como completude da série das causalidades. Por outro lado, se considerarmos 0 incondiconado como aquilo que não é condicionado por algo externo ou por algum conteúdo material, isto é, como causalidade por liberdade, também sob este aspecto pode-se pensá-lo sem contradição. Enquanto participante do mundo fenomênico (leis da causalidade natural) não sou livre. Estou submetido a estas leis. Posso e devo, contudo, pensar a liberdade enquanto ao mesmo tempo sou parte do mundo inteligivel. Ela passa a ser uma Idéia da razão. Deve ser possivel pensar uma ação por vontade própria, por vontade autônoma, isto é, sem nenhum condicionamento externo. Esta é condição para que a ação tenha mérito moral. A discussão sobre os dois mundos em Kant será retomada por ocasião da análise da possibilidade do imperativo categórico.

Podemos distinguir uma dupla função da crítica promovida por Kant: Uma negativa e outra positiva. Quanto à primeira, cumpre observar que ela fixa os limites da competência da razão - é uma "função policial" (cf. Beck, 1980, p. 44); mostra que a razão especulativa não pode elevar-se acima dos limites da experiência (cf. C. R. Pura, p. 15). Há uma restrição do uso da razão. Mas se por um lado esta restrição é negativa, por outro, é positiva, na medida em que assegura para a razão o caminho seguro da ciência e mostra que há um uso prático da razão - o moral - que ultrapassa os limites da sensibilidade. É a restrição do uso teórico que nos "convence" do uso prático da razão pura. O estabelecimento de um critério de cientificidade (que é restritivo) indica o que fica de fora do campo da ciência ou do âmbito da razão especulativa (teórica). Se o conhecimento científico deve começar pela experiência, mas seu resultado final não é só produto da experiência, mas também do entendimento, não pode uma "metafísica dos costumes" começar pela experiência. Estar-se-ia, então, fazendo "psicologia empírica" e não uma Filosofia prática (uma metafísica dos costumes) (cf. F. M. C. p. 66 ).

A crítica (da razão) é uma "avaliação da razão pura, das suas fontes e seus limites" (C. R. Pura, p. 33). Trata-se realmente de uma utilidade negativa, na medida em que não tem em vista uma ampliação, mas uma "purificação da razão" ou uma restrição do seu uso, a fim de preveni-la e mantê-la livre de possiveis erros. A crítica mostra, portanto, que todo possivel conhecimento da razão especulativa fica limitado aos objetos da experiência. Ela (a crítica) ocupa-se da razão mesma, 
do modo de conhecer e não dos objetos do conhecimento. É isso que Kant chama de transcendental: "Denomino transcendental todo conhecimento que em geral se ocupa não tanto com objetos, mas com o modo de conhecer objetos na medida em que este deve ser possível a priori" (C. R. Pura, p. 33).

A crítica diz que a razão pura, em seu uso teórico, não pode estender-se; limita seu uso. Ao fazê-lo indica ou mostra que há um uso prático da razão pura. Algo ficou de fora do uso teórico mas que também é um fato. Ou seja, assim como existem, de fato, juízos sintéticos a priori, existem também, de fato, proposições sintéticas práticas a priori (na forma de "conhecimento moral da razão vulgar"). A questão é: como são possiveis? A indicação dos limites (restrição do uso teórico da razão) é condição de possibilidade de acesso ao uso prático. A indicação dos limites do conhecimento conduz a um outro nível que é o do pensamento. "Se não podemos conhecer esses mesmos objetos como coisas em si mesmas, temos pelo menos que poder pensá-los" (C. R. Pura, prefácio). Para todo efeito deve ser procurada uma causa, e para completar a série das causalidades (e esta é uma exigência da razão) deve ser pensado um incausado (incondicionado). Se na parte analítica da Crítica da Razão Pura é negado o conhecimento para além dos objetos da experiência, fica, no entanto, salvaguardada a possibilidade e até a necessidade de pensar as coisas enquanto númenos (cf. C. R. Prática p. 55). Considerando que os fenômenos são meras representações, devem ter um fundamento além deles. Este fundamento é a coisa em si, da qual nada conhecemos mas que deve poder ser pensada como base de todo fenômeno. Para o mundo dos fenômenos impõe-se uma idéia reguladora que não pode ser conhecida, mas que deve ser pensada enquanto exigência discursiva da razão. A critica é que nos mostrou esta distinção entre as coisas como objetos da experiência e as coisas como em si mesmas. Se não posso conhecer as coisas em si mesmas devo poder pelo menos pensá-las, a partir daquilo que podemos conhecer (os fenômenos). Se os objetos aparecem sob diferentes aspectos é porque são muito mais do que aparece sob um determinado aspecto. O conhecimento, no entanto, só se refere ao que aparece num determinado aspecto, isto é, diz respeito ao espaço e tempo, condições de possibilidade da sensibilidade.

Há aqui uma separação em dois mundos: $O$ mundo do conhecimento e o mundo do pensamento; o mundo do saber e o mundo do ser. A razão prática situa-se no nível do pensamento, portanto, ao nivel do incondicionado, isto é, da "causalidade com liberdade"; da autonomia; do mundo inteligível. O acesso a este requer, no entanto, uma prévia "crítica" dos limites da razão pura teórica. A razão prática não pode buscar no mundo da experiência nenhuma fonte de determinação de seus princípios, uma vez que dele não resulta nenhum dever-ser. A experiência só diz o que é, mas não indica os princípios do que deve ser. Ou seja, exigem-se princípios para fundamentar algo que já é - o "conhecimento moral ordinário".

É a distinção entre fenômeno e coisa em si que permite, por exemplo, pensar a liberdade ao nivel da moral sem se cair em contradição. Enquanto submetido à necessidade natural (mundo dos fenômenos) minha vontade não é livre; enquanto participante do mundo inteligivel, sou livre. Aquela distinção é que me permite 
entender como uma vontade é livre e ao mesmo tempo submetida às leis da necessidade natural. A liberdade, portanto, não pode ser conhecida, mas deve poder ser pensada como condição de possibilidade do valor moral dos atos humanos. Ela passa a ser uma idéia reguladora, necessária para a razão prática. A idéia reguladora tem a função de ser um dever-ser para tudo o que é. Só é possivel emitir um juizo moral sobre o que é de fato a partir da idéia do que deve ser. Preciso, portanto, determinar princípios (reguladores) do que "deve acontecer", mesmo que não aconteça, mas que servem de referencial para julgar a (minha) situação presente. Estes princípios servem como uma "bússola" através dos quais a razão saberá distinguir o que é bom e o que é mau, o que é "conforme o dever" e o que é contrário a ele (cf. F. M. C. p. 35).

É importante salientar que é o primeiro momento (o da restrição do uso teórico da razão ao mundo dos fenômenos) que conduz e exige o segundo momento (o mundo inteligivel). Tanto a doutrina da natureza quanto a doutrina da moralidade mantém, assim, o seu devido lugar. Esta delimitação é possivel porque a "crítica" nos "instruiu sobre a nossa inevitável ignorância acerca das coisas em si mesmas e limitou a meros fenômenos tudo o que podemos conhecer teoricamente" (C. R. Pura, p. 17). Os princípios da razão prática (as leis objetivas-práticas), que dizem o que deve ser e não o que é, não são objetos de conhecimento, porque não se originam da experiência, mas são pensáveis, isto é, determináveis aprioristicamente, dada a capacidade não só intuitiva da razão, mas também discursiva. Assim, a lei moral, como veremos, vem a ser uma espécie de elo de ligação entre o "númeno" (o "eu penso"), atemporal e supra-sensivel, e os fenômenos de atuação prática, que são temporais e sensiveis (cf. Caffarena, 1988, p. 180). A lei moral deve ter efeitos sensiveis sobre o mundo fenomênico, embora não possa partir deste como seu fundamento.

A crítica é, de certa forma, uma atividade preventiva na medida em que investiga a razão especulativa quanto à sua capacidade de conhecimento. Ela propõe-se estabelecer uma delimitação exata entre o campo da ciência e o da metafísica. Evita, com isso, pensa Kant, inúteis disputas entre estas sobre seu campo de atuação. Esgotados os limites do uso teórico da razão (que se referem às condições de possibilidade do conhecimento) mostra a possibilidade e a necessidade de ultrapassar estes limites para encontrar na razão mesma (já que não pode encontrar fora dela) e justificar os principios fundadores do agir humano já vigentes na forma de "entendimento moral popular". Se estes princípios fossem tirados da experiência, os atos humanos com eles concordantes não teriam valor moral, quando muito, valor legal. Como veremos, princípios empíricos nunca servem para sobre eles fundar leis morais (cf. F. M. C. p. 87). Tais princípios não se caracterizam pela necessidade e universalidade, portanto, não seriam a priori; estariam "patologicamente afetados" pela subjetividade (cf. tb. Caffarena, 1988, p. 178 e 179). Isto é um fato para o "conhecimento moral popular".

Kant faz, portanto, uma metafísica purificada pela crítica. Isto significa que seus objetos só são atingidos depois de esgotadas todas as possibilidades de encontrá-los no campo da sensibilidade. Na Crítica da Razão Pura, escreve: "Quando a razão aprendeu a conhecer completamente a sua própria faculdade no tocante 
aos objetos que podem lhe ocorrer na experiência, tem que se tornar fácil determinar completa e seguramente o âmbito e os limites do seu tentado uso acima de todos os limites da experiência" (C. R. Pura, p. 32). A insistência de Kant vai no sentido de mostrar que todas as tentativas de fazer especulações no campo suprasensível são ilegítimas enquanto antes não se submeter a razão ao crivo da crítica; isto é, enquanto não se indicar os limites do conhecimento no mundo sensível, ou ainda, enquanto não se fizer um "exame prévio da capacidade ou incapacidade da razão" (C. R. Pura, p. 25).

Estas indicações mostram que os princípios da ética kantiana, especificamente o imperativo categórico e suas diferentes formulações, são resultado de um processo de avaliação da razão humana e de suas capacidades e não produto de um ponto de partida meramente arbitrário e dogmático.

Fazer uma crítica da razão pura teórica, isto é, uma crítica transcendental, significa estabelecer as condições de possibilidade do conhecimento, portanto, as condições de possibilidade da ciência, condições estas dadas pelo sujeito (razão pura) e não pelo objeto. Este não pode dar o a priori. Fazer uma crítica da razão prática significa mostrar que uma razão pura pode ser prática, isto é, que ela pode, por si mesma e independente de um conteúdo empírico, portanto a priori, determinar a vontade dos sujeitos agentes. É a mesma razão pura com dupla função ou duplo uso: uma teórica e outra prática. É a aplicação que as diferencia. Uma prévia teoria do conhecimento, ao mostrar os limites da razão pura teórica, dá acesso à razão pura prática. A segunda deve ser precedida pela primeira. Ambas são razão pura. Em conjunto formam a filosofia transcendental. Há uma unidade entre razão pura teórica e razão pura prática no que se refere ao caráter a priori de seus princípios. Estes são sempre independentes da experiência. $O$ que as distingue é sua diferente aplicação (cf. tb. Caffarena, 1988, p. 177).

Já podemos adiantar (o que será visto nos próximos capítulos) que a divisão kantiana em dois mundos - o mundo dos fenômenos e o mundo dos númenos será totalmente abandonada por Hegel e já mesmo antes dele, por Fichte. Igualmente esta tentativa de esgotamento da capacidade de uma razão pura teórica não sobreviverá à filosofia posterior. A separação entre o âmbito do conhecimento e o âmbito do pensamento tornar-se-á insustentável. A unidade da razão será pressuposto básico no sistema hegeliano. Uma razão pura, na verdade, já é deste sempre prática. Não é uma prévia crítica do conhecimento que dará acesso a ela. Não há possibilidade de um esgotamento das capacidades da razão. A razão jamais poderá conhecer-se completamente. Além disso, o conhecimento já se refere desde sempre à coisa em si. O que é, já sempre é um dever ser, mesmo que aquilo que é seja sempre realização parcial do que deve ser. 


\section{Referências bibliográficas}

BECK, L. W., A commentary on Kant's critique of pratical reason. Londres, The University of Chicago Press, 1980.

CAFFARENA, E. Gomez. Razón Prática, Razón Utópica. In: Agora: Papeles de Filosofia.

Santiago de Compostela: Imprenta Universitária, 1988, p. 177-192.

KANT, I . Crítica da Razão Prática. Lisboa, Ediçōes 70, 1986. (Trad. de Artur Morão).

- Fundamentação da Metafísica dos Costumes. Lisboa, Edições 70, 1986. (Trad. de Paulo Quintela)

- Critica da Razão Pura: São Paulo: Abril Cultural, 1980.

HEGEL, G. W. F.Grundlinien der Philosophie des Rechts. Frankfurt am Main, Suhrkamp, 1986. 